\title{
Un "partido" de "indios y christianos". Formas de organización y dinámicas de acción colectiva en la jurisdicción de Jujuy (1781)
}

Lucía Glatstein"

Fecha de recepción: 11 de mayo de 2018. Fecha de aceptación: 23 de septiembre de 2018

\section{Resumen}

En este artículo examinamos formas de organización y dinámicas de acción colectiva durante un episodio que ocurrió en la jurisdicción de Jujuy en 1781. Hacia fines de marzo de ese año, indígenas chaqueños, soldados partidarios de la frontera, otros habitantes de la zona sur oriental y la "plebe" de la ciudad se habrían preparado por medio de distintas acciones para atacar la ciudad de Jujuy. El análisis se centra en distinguir las maneras en que se realizaron las convocatorias a participar, los canales y modos de circulación de información y los desplazamientos de personas por la jurisdicción. Buscamos identificar, además, los procesos de toma de decisiones, las formas de repartir las tareas y la estructura interna del movimiento. Nuestro interés radica en reconstruir los significados de las prácticas y las visiones que sobre el orden colonial tenía la población de la jurisdicción de Jujuy a fines del siglo XVIII.

\section{A "party" of "Indians and Christians". Organization forms and dynamics of collective action in the jurisdiction of Jujuy (1781)}

\begin{abstract}
In this article we examine the organization and dynamics of collective actions during an episode in the jurisdiction of Jujuy in 1781. Towards the end of March of that year, indigenous people from Chaco, soldados partidarios -soldiers who defended the border-, other inhabitants of the southern oriental zone and the city "plebeians", would have been preparing an attack to the city of Jujuy. The proposed analysis focuses on how the calls for participation were made, the channels and modes of circulation of information and the movements of people in the jurisdiction. Moreover we seek to identify processes of decision making, the distribution of tasks and the internal structure of the movement. Reconstructing the meanings of the practices and visions the population of Jujuy's jurisdiction had, regarding the colonial order at the end of the XVIII century is our main concern.
\end{abstract}

* Instituto de Humanidades, Consejo Nacional de Investigaciones Científicas y Técnicas (CONICET)/ Universidad Nacional de Córdoba. Córdoba, Argentina. E-mail: luciagla86@gmail.com

\section{Palabras clave}

Jujuy acciones colectivas proyectos y percepciones políticas 1781

\section{Keywords}

\section{Jujuy}

collective actions political projects and perceptions 1781 
1. Cabe destacar que el expediente reúne, además, la pesquisa que se desarrolló en la Puna de Jujuy a raíz de la presencia de un edicto que se presumió era de Damaso Katari y de cartas provenientes de Lipes que convocaban a las poblaciones de la jurisdicción a participar en la guerra en Charcas. Las pesquisas realizadas en las tierras altas fueron anexadas al proceso judicial, sobre el que basamos principalmente nuestro análisis, una vez que el mismo había comenzado. Del total de acusados y ejecutados señalados, tres estuvieron vinculados con las acciones colectivas que se desarrollaron a principios de abril de 1781 en la Puna. Para un análisis sobre la construcción del expediente y de los argumentos de las autoridades coloniales, ver Glatstein (2017).

\section{Introducción}

Hacia marzo de 1781, los vecinos de la ciudad de San Salvador de Jujuy tomaron conocimiento de que, hacia los valles surorientales y el espacio fronterizo con el Chaco, se había conformado una amenazante alianza entre indígenas chaqueños reducidos, soldados partidarios de los fuertes de la frontera y otros habitantes que trabajaban en las unidades productivas de la zona. Temían además que participasen en ella la "plebe" de la ciudad e indígenas chaqueños "infieles". Frente a esta novedad, el cabildo español de Jujuy junto al teniente del gobernador del Tucumán iniciaron de oficio, y por razón de estado, un proceso judicial y movilizaron tropas que apresarían a los sospechosos de participar de una traición a la corona española en la jurisdicción de Jujuy. Los jueces se interesaron por esclarecer los hechos que se desarrollaron del 24 de marzo al 4 de abril y, por lo tanto, la pesquisa se centró en recoger información sobre la toma de la reducción de San Ignacio y del fuerte de Ledesma, el sitio del cercano fuerte de Río Negro, la realización de convocatorias por diferentes parajes de la jurisdicción y la concreción de reuniones en sitios específicos. El argumento que sostuvo la indagatoria fue que las insurrecciones en el virreinato del Perú y la Audiencia de Charcas habían trascendido hasta la jurisdicción y que con estas prácticas una parte específica de su población se preparaba para atacar Jujuy en nombre de Tupac Amaru. Por medio de tres sentencias -que no demoraron en comenzar a pronunciarse- se acusó del delito de lesa majestad a cuarenta y un personas, de las cuales veinticuatro recibieron la pena de muerte. ${ }^{1}$

Este episodio tuvo lugar en el momento más álgido de la "era de la insurrección andina", cuando ya eran numerosas las regiones inmersas en la guerra civil que entre 1780 y 1782 puso en vilo al dominio colonial español en los Andes centrales y meridionales (Stern, [1987] 1990b). Partiendo de un estudio previo que se centró en la intervención de las autoridades coloniales (Glatstein, 2017), examinaremos aquí las formas de organización y dinámicas de acción colectiva, observando y distinguiendo las maneras en que se realizaron las convocatorias a participar, los canales y modos de circulación de información y los movimientos de personas por el espacio de la jurisdicción. Buscamos comenzar a identificar, además, los procesos de toma de decisiones, las formas en que se repartieron las tareas y la estructura interna del movimiento.

Nuestro análisis recupera distintas propuestas de investigaciones que abordaron -de acuerdo con las denominaciones escogidas como más apropiadas por cada investigador- revueltas, rebeliones, sublevaciones o insurrecciones en distintos contextos y períodos históricos, que poseen como común denominador el considerar que los campesinos, la plebe u otros sectores subalternos moldearon relaciones y concepciones políticas originales de forma activa y continua. Siguiendo a Thompson ([1971] 1979) y Scott ([1976] 1977), buscamos alejarnos de perspectivas que consideren los movimientos sociales como reacciones caóticas y espasmódicas de los grupos subordinados, para pasar a priorizar el revelar las lógicas a partir de las cuales situaciones de explotación se tornaron injustas y se articularon acciones de violencia con una organización particular. En consonancia, tomamos las propuestas de etnohistoriadores para un uso crítico y adaptado al contexto andino de esta perspectiva. Entre los aspectos más destacados, esto supone incorporar la etnicidad en las explicaciones, considerar los procesos de resistencia y adaptación en la larga duración y entender la violencia colectiva como parte del repertorio más amplio de 
formas cotidianas de negociación y protesta de los grupos subalternos con las formaciones políticas y económicas coloniales (Stern, [1987] 1990a; Larson, 1992; Thomson, 2003, [2006] 2010 y Serulnikov, 2006). Asumimos que, aunque nos centramos en un momento de agitación colectiva y en las prácticas que se ejecutaron en ese lapso específico, el estudio de las formas de participación política no puede disociarse de los procesos de construcción de las estructuras imperiales o estatales, de las cuales los sectores subordinados participaban cotidianamente (Joseph y Nugent, 2002) con distintas posibilidades según los períodos de avance o retroceso de la penetración del estado y el mercado (Larson, 1992: 84).

El análisis estará sustentado en fuentes que se encuentran actualmente en el Archivo General de Indias (Sevilla, España) y en compilaciones editadas. Se trabajará principalmente con el documento resultante del proceso judicial que se realizó en la jurisdicción de Jujuy entre 1781 y 1782 para identificar y castigar a los presuntos traidores a la Corona española. De forma complementaria, se consultará la información presente en distinta correspondencia, en informes de méritos y servicios, decretos y reales órdenes generados en forma contemporánea al accionar de la justicia. Se trata de documentos producidos en su totalidad por agentes de la administración colonial que poseen una lógica de representación particular, que entendemos fue diferente a aquella que guiaba las acciones y prácticas políticas de quienes estuvieron involucrados en las acciones colectivas. ${ }^{2}$ Los sospechosos de tal participación -la mayoría entre los 58 testigos del juicio- formaban parte de la sociedad multiétnica asentada en tierras bajas desde mediados del XVIII. Identificados como criollos, indios, cholos, mulatos y mestizos que trabajaban en la reducción, en los fuertes o en las unidades productivas de los valles, fueron frecuentemente agrupados bajo la denominación de "gente plebe" o "gente baja". Sus testimonios nos permiten inferir las prácticas de las parcialidades indígenas del Chaco que no fueron llamadas a declarar, ${ }^{3}$ profundizar sobre los principales hechos que tuvieron lugar hacia los valles surorientales y conocer que -además de aquella noticia que aseguraba que la "gente plebe" se aprestaba a asaltar la ciudad de Jujuy- se intercambió información sobre la coronación del "Rey Inka" en el Perú y se habló de que los "españoles" estaban matando a la "gente plebe" de la jurisdicción o que iban a hacerlo de manera inminente.

Teniendo presente todo lo expuesto consideramos que durante el desarrollo del episodio, en el que acciones colectivas concretas fueron rápidamente reprimidas por las autoridades coloniales de la jurisdicción de Jujuy y de la Gobernación del Tucumán, se pusieron de manifiesto relaciones sociales y de poder que surgieron de las dinámicas que se trazaron en la región especialmente desde mediados del siglo XVIII, cuando el espacio de la frontera oriental avanzó desde los límites de la ciudad hasta llegar al valle de San Francisco. Distintas investigaciones sostienen que en aquel contexto la articulación de fuertes, unidades productivas y reducciones, facilitó la estabilidad de la presencia colonial en un área controlada por grupos indígenas chaqueños $\mathrm{y}$, además, habilitó espacios para contactos cotidianos entre éstos, los soldados partidarios encargados de la defensa de la frontera y migrantes surandinos que trabajaban en las tierras de las haciendas y estancias o en sus pequeñas chacras. También participaban de la interacción diaria los capitanes de los fortines, los religiosos de las reducciones y los vecinos de la ciudad que poseían intereses en las tierras orientales -donde procuraban asentar o consolidar sus empresas agropastoriles. Cabe destacar que los estudios afirman que el traslado hacia este espacio supuso una expectativa de ascenso social que solo habría podido cumplimentarse por unos pocos individuos -los comandantes de la frontera,
2. Recuperamos este recaudo metodológico para el trabajo con fuentes coloniales americanas de Serulnikov (2006).

3. Juzgamos importante destacar que todo lo que logramos saber de la intervención de los indígenas del Chaco -ya sea de las parcialidades reducidas en la misión de San Ignacio o de los matacos "infieles"proviene de lo que el resto de los participantes dijo sobre ellos. 
4. Las dinámicas del espacio oriental de la jurisdicción de Jujuy fueron reconstruidas en base a los trabajos específicos de: Vitar (1991 y 1997), Gullón Abao (1993), Teruel (1994), Sánchez y Sica (1997), Sánchez (2002), Mata de López (2005), Lucaioli y Nesis (2007), Nacuzzi (2007) y Lucaioli (2009 y 2010). los capitanes de los fuertes y los vecinos de la ciudad-, siendo relegada a un lugar marginal el resto de la población. Sostienen asimismo que el vínculo con las parcialidades chaqueñas no dejó de ser ambiguo luego de mediados del XVIII. Sin ser del todo incorporadas al sistema colonial, algunas parcialidades aceptaron reducirse en las misiones religiosas pero continuaron con sus ciclos de movilidad -incluyendo a la reducción dentro del espacio por el que transitaban- $\mathrm{y}$-en algunas ocasiones- mantuvieron periódicas incursiones a las estancias y haciendas que se ubicaban al este de la ciudad para obtener recursos. ${ }^{4}$ Creemos que en esa cotidianeidad están las bases para comprender las solidaridades y las alternativas políticas que se tejieron en los movimientos excepcionales de 1781.

Quisiéramos, antes de adentrarnos de lleno en el análisis empírico, realizar una última salvedad sobre el alcance de nuestros objetivos e hipótesis a partir de un sugerente fragmento extraído de un trabajo centrado en una revuelta que aconteció en París a mediados del siglo XVIII y cuya lógica parecía "ambigua" o "evanescente en las fuentes". Los investigadores expusieron la siguiente reflexión:

Si el motín atrae a tantos participantes, venidos de horizontes tan diversos, no es porque algunos profesionales del desorden han logrado arrastrarlos. Es porque más allá de la monótona repetición de los movimientos de la multitud, sus gesticulaciones y gritos, la misma propone a aquellos que se reúnen cierta cosa en común, un objetivo sin dudas pero todavía más, un lenguaje que se elabora en el corazón del acontecimiento y que da a cada uno las razones de su propia acción. Podemos entonces intentar leer la revuelta como un texto que los actores improvisan, aunque valiéndose de antiguos guiones. Este ejercicio no tiene más de arbitrario que lo que tiene de convencional. Eligiendo lugares, situaciones o deteniendo un ajuste de cuentas, los revoltosos inventan, de episodio en episodio, la significación de su revuelta (Farge y Revel [1988] 1998: 67).

Respecto a interpretaciones existentes sobre la serie de acciones colectivas de Jujuy que acapara nuestra atención (Lewin, 1957; Acevedo, 1960; Poderti, 1997; Sánchez, 2002; Cruz, 2006, 2011), buscamos precisar la "elaboración progresiva" de la movilización colectiva a partir de las mismas prácticas que ejecutaron quienes se vieron envueltos en su desarrollo (Farge y Revel, [1988] 1998: 9). Se trata de observar su especificidad dentro de un contexto andino convulsionado y así contribuir a apreciar -como lo alentara Thomson (2003)- la gran variedad de experiencias históricas que se incluyen en lo que se conoce como la "Gran Rebelión" de 1780-1782.

\section{El escenario de los movimientos}

Como se infiere de las palabras introductorias y como se podrá observar con mayor precisión en los siguientes apartados, los movimientos adquirieron mayor intensidad -o estuvieron a punto de hacerlo- alrededor de determinadas instituciones y espacios.

Tanto los fuertes de Ledesma y del Río Negro como la reducción de San Ignacio se encontraban en el valle de San Francisco, es decir, en la zona de los valles orientales que se ubica al este de la Quebrada de Humahuaca y que Lorandi caracterizó como una "franja de transición" entre los ambientes de las sierras andinas y la llanura chaqueña (Lorandi, 1980: 148). Era para la jurisdicción 


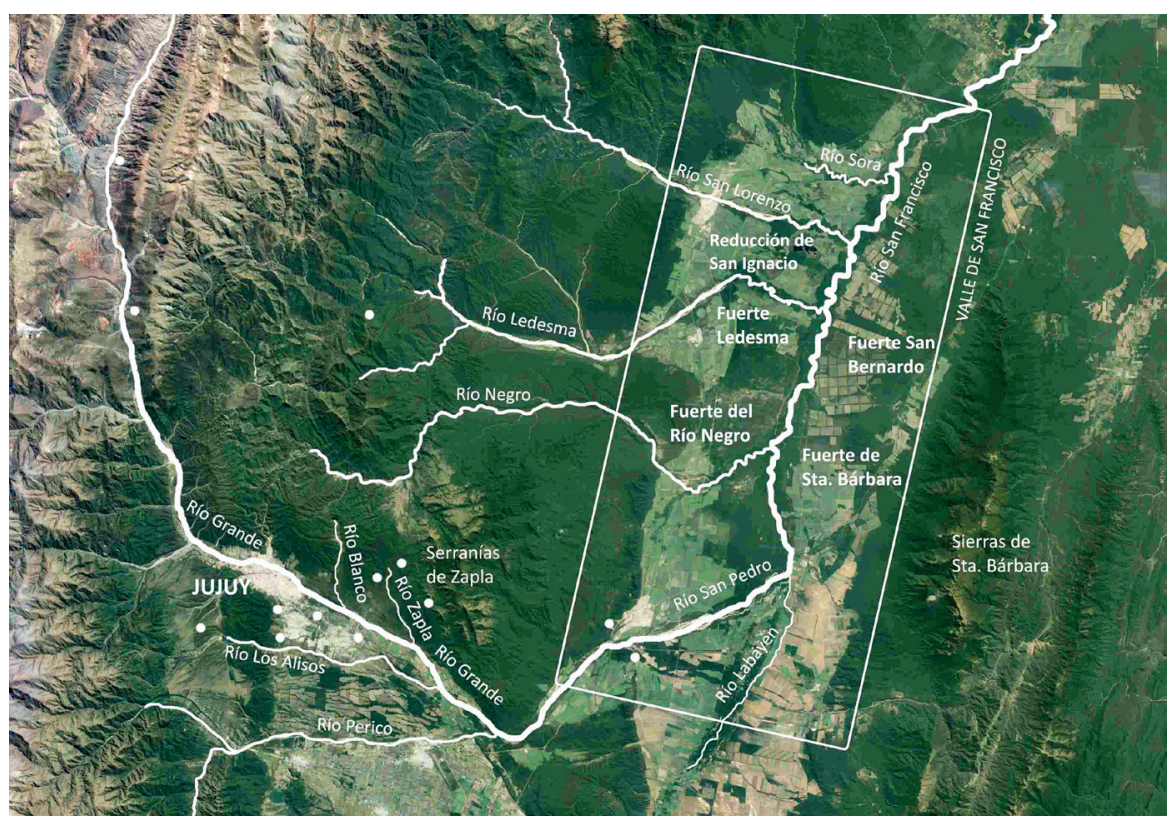

Mapa de elaboración propia.

del cabildo de Jujuy un espacio de reciente incorporación y hacia 1781 aún mantenía su carácter de frontera (Sánchez, 2002).

La reducción de San Ignacio se fundó a mediados del siglo XVIII, a partir de pactos con indios "tobas" fronterizos de Jujuy como uno de los medios para avanzar sobre el territorio indígena no dominado. Si bien en un principio se había pensado en instituciones que fomentaran la sedentarización de los grupos nómades del Chaco y su aislamiento de parcialidades no reducidas, con la experiencia se fue apreciando la dificultad de mantener rigurosamente esta política. Además, la dispersión de los indios reducidos parece haber aumentado rápida y significativamente con la expulsión de los jesuitas, lo que implicó una merma de los bienes europeos que hasta el momento obtenían por medio de la administración que realizaba esta orden religiosa y la necesidad de salir de la misión para conseguirlos. ${ }^{5}$ Hacia 1771 aparecen consignados aproximadamente 300 indios dentro de San Ignacio, la mitad en relación al período jesuita (Teruel, 1994; Vitar, 1997). En marzo de 1781 conocemos -por los relatos del proceso judicial- que al menos dos parcialidades tobas con sus respectivas autoridades étnicas se encontraban en la reducción, las que aparentemente asumieron -como veremos- distinta posición frente a los hechos que se desencadenaron a principios de ese otoño de $1781{ }^{6}$

Los fuertes de Ledesma y de Nuestra Señora de Dolores del Río Negro se instalaron a comienzos de la década de 1710 y a finales de la década de 1740, respectivamente. ${ }^{7}$ Con estas instituciones -y con los soldados partidarios que ocupaban sus plazas- se esperaba disuadir posibles incursiones indígenas o -llegado el caso- advertir velozmente a los colonos para que pudieran resguardarse. ${ }^{8}$ Desconocemos cuál era el número exacto de soldados partidarios destinados a estos fortines y, por ende, al exclusivo cuidado de la frontera hacia marzo de 1781, pero -si nos guiamos por la investigación de Gullón Abao (1993: 198-231)- podemos afirmar que debía rondar en unos diecinueve en el Ledesma y otros treinta y tres en el Río Negro. En el proceso judicial quienes ocupaban estos puestos, cuando se desencadenaron los eventos que nos interesan reconstruir, fueron mayormente anotados como naturales de jurisdicciones de la gobernación del Tucumán -predominando los de Jujuy sobre los de
5. El ganado vacuno fue uno de os bienes más importantes para asegurar a los indígenas chaqueños en la reducción, pero mermó luego de la expulsión de los jesuitas (Teruel, 1994).

6. AGI, Buenos Aires 143, Autos del proceso judicial.

7. Otros dos fuertes se ubicaron en el Valle de San Francisco: San Bernardo y Santa Bárbara, ambos en 1749 (Gullón Abao, 1993).

8. Garavaglia (1984: 22) sostiene esta tesis respecto a la función de los fortines fronterizos, entendiendo que no debió ser su tarea principal contener un ataque. 
9. Declararon en el proceso judicial once soldados partidarios; otros once aún estaban prófugos cuando se cierra el expediente $y$ desconocemos si su número era mayor. La errática información sobre los últimos la hemos podido extraer de las declaraciones de quienes fueron apresados 0 se presentaron a dar testimonio.

10. Las referencias corresponden al proceso judicial y a un bando enviado a publicar por el alcalde de primer voto de Jujuy, en búsqueda de soldados partidarios prófugos, al cual tenemos acceso a través de una transcripción parcial de Farberman (2009).

11. AGI, Buenos Aires 143 , Declaraciones de José Quiroga, Francisco Ranjel, Juan de Dios Maldonado, Juan José Almasan y José Domingo Morales, fs. 37v, 51v, $65 \mathrm{v}, 218 \mathrm{v}$ y $231 \mathrm{v}$.
12. AGl, Buenos Aires 143, Declaraciones de José Quiroga, Francisco Ranjel, Juan de Dios Maldonado, Juan José Almasan y José Domingo Morales, fs. 37v, 51v, $65 \mathrm{v}, 218 \mathrm{v}$ y $231 \mathrm{v}$.

13. AGI, Buenos Aires 143, Ratificación de Juan de Dios Maldonado y Declaración de José Quiroga, fs. 9ov-92r y fs. 218v-225r.
Santiago del Estero- y algunos como provenientes de la Audiencia de Charcas -de las provincias de Tarija y Cinti específicamente. ${ }^{9}$ Además, se los registró a raíz de su propia descripción o la realizada por las autoridades como "de la clase de españoles", "indio amulatado", "mestizo", "no muy ladino en habla castellano", "criollo", "blanco de cara" o "de cuerpo blanco", "indio", etc. ${ }^{10}$ y se señaló que mencionaron llevar largo tiempo trabajando en los fuertes o en la reducción. ${ }^{11}$ Gullón Abao (1993: 198-231) aclara que estos sujetos estaban bajo el mando de los comandantes de los fuertes, quienes dependían asimismo de los gobernadores de armas designados por el gobernador del Tucumán, como responsables del cuidado de la frontera. Ambos cargos eran prioritariamente ocupados por peninsulares o hijos de vecinos españoles. Las investigaciones de Gullón Abao (1993) sugieren además que fue cada vez más recurrente que estas dos autoridades utilizaran a la gente bajo su mando y a los indígenas -tanto reducidos como "amigos" o cautivos- en las unidades productivas que instalaron en las tierras contiguas a los fortines.

Hacia fines del siglo XVIII la ciudad de Jujuy era el espacio donde residía la mayor parte de los españoles de la jurisdicción, una minoría entre indígenas y mestizos. Según la información recopilada en la cabecera durante el censo de 1778/79, sobre un total de 2.000 habitantes entre los que se consignaron mestizos (25\%), mulatos (21\%), negros (15\%) e indígenas $(14 \%)$, los españoles representaban el $24 \%$ de la población (Rasini, 1965). Un tercio de ellos, conformaba la elite de la jurisdicción que había acumulado la posesión de la tierra, que se beneficiaba considerablemente del comercio y que detentaba el poder político local mediante oficios regios y capitulares (Paz, 1997).

\section{El "inicio" de la reducción de san Ignacio}

Según se desprende del relato de la primera deposición del proceso judicial que a lo largo de un año buscó resolver sobre el asunto, todo habría comenzado con el ingreso a la reducción de San Ignacio de indios tobas de un hombre cuya identidad se desconoció en un principio. O, por lo menos, esa fue la impresión que dejaron traslucir las autoridades y vecinos de Jujuy en la resolución de la instancia judicial y en distintos informes elevados a otros funcionarios reales. A partir de las circunstancias que rodearon la presencia de este sujeto en la reducción hacia fines de marzo de 1781 consideraron que se enfrentaban indefectiblemente con una "sublevación" en la jurisdicción de Jujuy, que describieron en la forma de una "alianza" entre criollos, mestizos, mulatos e indios que se preparaba para atacar la ciudad de Jujuy (Glatstein, 2017).

El 26 de marzo el cabildo de Jujuy había recibido un comunicado desde la reducción que informaba "la altaneria y ninguna subordinacion con que se manejan los mencionados indios combersos" y el 28 de marzo otro informe aseveraba que los indios estaban "sublebados...como partidarios de Tupamaro". Entre ambas fechas, se produjo el ingreso de quien fuera reconocido como José Quiroga. ${ }^{12}$ Muchos testimonios, incluido el suyo propio, aseveran que fue a solicitar ayuda en tanto se le había asegurado que los españoles matarían a toda la "gente plebe" de la jurisdicción y porque ya era conocida la coronación del "Rey Inka" en el Perú. ${ }^{13}$

Descripto como "criollo", en su declaración agregó que era natural de Santiago del Estero y vecino de la ciudad de Jujuy donde había sido ordenanza en las cajas reales por un año y donde residía desde hacía varios meses. Explicó que anteriormente, "desde sus tiernos años", se había desempeñado como soldado 
partidario de uno de los fuertes ubicados en el valle de San Francisco, en las cercanías de la reducción. ${ }^{14}$ Quiroga afirmó en su declaración que "sin duda tomo él esta comision [de convocarlos] por el conocimiento que tenia de los indios" y "por la amistad que tenia con ellos desde el tiempo que fue soldado partidario en el fuerte". ${ }^{15}$

Por lo que pudimos reconstruir Quiroga salió de la casa de un pariente suyo, que habitaba en el paraje de Zapla, con la información referida y fue pasando por las habitaciones de otras personas hasta llegar a las inmediaciones de la reducción, donde se encontró con un grupo de soldados partidarios que tenían sus puestos en ella. En estos primeros encuentros -en los cuales las personas dijeron haber sido sorprendidas en sus quehaceres- fue comunicando las novedades y su objetivo de reunirse con los indios. Matías Pino, por ejemplo, manifestó que Quiroga se presentó en su casa

y le encargo que de ningun modo biniese a Jujui [porque estaban matando a toda la gente] y que él se hiba en busca de los indios a ver si encontraba favor de ellos, y que le dio de almorzar e immediatamente monto en su cavallo y se fue. ${ }^{16}$

Juan Ossorio, por su parte, asentó en su declaración que luego de "enredarse en conversación" y comunicarle sobre la coronación del Rey Inka y su intención de buscar a los tobas para atacar la ciudad, le insistió que "el dia lunes estubiese pronto que por alli havia de pasar con los indios encargandole assimismo que convocase a todos sus amigos para este hecho".${ }^{17}$ Uno de los soldados de la reducción expuso que al encontrarse con Quiroga este le refirió -además de la amenaza que recaía sobre la "gente plebe"- que:

\section{se rezelaban los españoles que se alzasen [los soldados] por que no havia plata con que pagarles lo que havian servido" [y] "les aconsejo que se saliesen [de la reducción] porque ya benian los blanquillos quienes havian de ir a pasarlos a cuchillo...con lo que se pasaron a su destino y el dicho Quiroga les dijo que iba a ver a los indios. ${ }^{18}$}

No se aprecian actitudes coactivas ni apremiantes, como sí se distinguen en las descripciones que los testigos hicieron sobre las convocatorias de los próximos días como veremos. No queda del todo claro si al entrar a la reducción ya iba acompañado de otros habitantes de los valles surorientales y de parte de los soldados partidarios de ella, pues al ser citados por la justicia a declarar los testigos van a procurar dar a entender que no participaron de ninguno de los hechos que se dieron en su interior. ${ }^{19}$

Carecemos, por ende, de precisiones sobre los términos del diálogo que se mantuvo con los tobas reducidos. Aparentemente -según la declaración de Quiroga- ya habían acordado el día en que saldrían de la reducción cuando el teniente de la misma quiso apresarlo. ${ }^{20}$ En el registro del testimonio del capataz de la estancia de la reducción se lee que los indios de la parcialidad del cacique Santiago evitaron el apresamiento de Quiroga, y luego ejecutaron al teniente cuando este insistió en negar la existencia del rey indígena. En la primera instancia en que se alteraron los ánimos otra parcialidad de indios tobas, bajo la autoridad del cacique Tesodi, defendió al teniente pero en un segundo momento, en el que este otro grupo ya no se encontraba en la reducción, no pudo salvar su vida tras increpar a quienes allí estaban por sus referencias a la coronación del "Rey Inka", destacando la existencia de un único rey (el
14. Si nos guiamos por el Diario de la expedición al Chaco de 1780, escrito por su comandante Juan Adrián Cornejo (en De Angelis, [1836] 1910: 40), estimamos que su plaza en el fuerte fue borrada hacia mediados de 1780 cuando buscó participar de la expedición hacia la ciudad de Corrientes.

15. AGI, Buenos Aires 143, Declaración de José Quiroga, fs. $218 \mathrm{v}-225 \mathrm{r}$.

16. AGI, Buenos Aires 143, Declaración de Matías Pino, fs. 225v-226r.

17. AGI, Buenos Aires 143, Declaración de Juan Ossorio, fs. $2 \mathrm{r}-2 \mathrm{~V}$

18. AGI, Buenos Aires 143, Declaración de José Domingo Morales, fs. 231v-232r.

19. AGI, Buenos Aires 143 , Declaraciones de Juan Ossorio, José Quiroga, Matías Pino y José Domingo Morales, fs. 2r-3r, $218 \mathrm{v}-225 \mathrm{r}, 225 \mathrm{r}-228 \mathrm{r}$ y $231 \mathrm{v}-237 \mathrm{v}$.

20. AGI, Buenos Aires 143, Declaración de José Quiroga, fs. $218 v-225$ r. 
21. AGl, Buenos Aires 143, Declaración del Negro Justo, fs. $7 \mathrm{v}-10 \mathrm{r}$.

22. AGl, Buenos Aires 143, Declaración de José Domingo Morales, f. $232 \mathrm{v}$.

23. AGl, Buenos Aires 143, Declaración de Miguel Geronimo Mamani, f. 49v: "en cuio tiempo se enfermo el declarante y viendo los indios que estaba inavil para ayudarles lo despacharon a la reducion [sic] al cuidado de la chusma donde estubo algunos días".

24. AGl, Buenos Aires 143 Declaraciones de José Alemán, Miguel Gerónimo Mamani, Melchor Ardiles y Manuel Romero, fs. $47 \mathrm{v}$, $49 \mathrm{v}, 55 \mathrm{r}, 57 \mathrm{v}$.

25. AGl, Buenos Aires 143 Declaraciones de Martín Vidaurre, Joachin Jurado, José Alemán, Miguel Geronimo Mamani, Manuel Romero y Juan Jose Chorolque, fs. $18 \mathrm{v}, 22 \mathrm{r}, 47 \mathrm{r}, 49 \mathrm{r}, 57 \mathrm{v}$ y $12 \mathrm{or}$. Por las fechas en que dijeron haber llegado al fuerte aquellos declarantes que estaban "de socorro" en Ledesma, intuimos que fueron enviados allí a raíz de las noticias que llegaron a la ciudad sobre los movimientos.

26. AGl, Buenos Aires 143, Declaración de José Alemán, f. $46 \mathrm{v}$. El resaltado en cursiva nos pertenece.

27. AGI, Buenos Aires 143, Declaración de José Alemán, f. 46v.

28. AGI, Buenos Aires 143, Declaración de José Quiroga, f. 221r. español). ${ }^{21}$ Pasadas estas tensiones, se nombró al menos a un capitán entre los soldados partidarios y un grupo salió en dirección al fuerte de Ledesma. ${ }^{22}$

San Ignacio no fue del todo abandonado. Esta institución se mantuvo dentro de la órbita de los movimientos, incluso cuando el avance de la marcha de soldados proveniente de la ciudad tomó prisioneros y provocó la huida de quienes estaban involucrados en las acciones colectivas. Mientras éstas se desarrollaban, permanecieron en la reducción las mujeres de los soldados partidarios, algunos enfermos y un grupo indeterminado de personas que en algunos testimonios aparece mencionado como la "chusma". ${ }^{23}$ Quienes salieron, en la continuación de las acciones colectivas, regresaron en distintas oportunidades para proveerse de recursos. Fue el caso de Melchor Ardiles, por ejemplo, quien expondrá en su declaración que una vez que desertó del fuerte del Río Negro se dirigió hacia la reducción para hacerse de un caballo, tomando uno que había sido retenido como "espolio de guerra". ${ }^{24}$ En los documentos no hay referencias que den cuenta de que la parcialidad del cacique Tesodi hubiese regresado a la misión durante los movimientos o luego del avance militar. Tampoco podemos afirmar si se plegó al movimiento, si contribuyó a sofocarlo o se mantuvo al margen.

\section{“Y a continuación...": El avance sobre los fuertes}

Mientras la reducción se mantenía tomada, el movimiento continuó en el fuerte de Ledesma el lunes 26 o martes 27 de marzo. Cuando llegó el grupo conformado -al menos- por indios tobas y soldados de la reducción de San Ignacio se encontraban en este fuerte su capitán, escasos soldados partidarios y algunas personas que habían sido enviadas "de socorro". ${ }^{25}$ Uno de los testimonios vuelve a hacer alusión al vínculo que existía entre los indios de la misión y los soldados partidarios de la frontera oriental, cuando José Alemán que estaba ocupando ese puesto en el Ledesma afirmó que "haviendole tocado el hazer centinela estaba en el cubo del fuerte cumpliendo con su obligacion, y a este tiempo...haviendose acercado los indios conocieron al declarante que estaba de centinela". ${ }^{26}$

La mayoría de las declaraciones de quienes se encontraban en el fuerte cuando se produjo el avance apuntan a que finalmente todos se sumaron a los recién llegados. Nos resulta dificultoso afirmar si lo hicieron voluntariamente o no. En el marco de los interrogatorios y careos los relatos resultan contradictorios, como puede observarse en la continuación del testimonio citado, donde primero se menciona que al reconocerlo, "le dijeron que bajase [del cubo del fuerte] porque de no lo havian de matar por cuio miedo viendo que las fuerzas estaban por ellos se bajo y se fue a su parcialidad con otros compañeros suios y assi se introdujo entre los indios"; y luego en la misma declaración agrega que "juzgandose necesario para ellos, se salio y se entrego voluntariamente, manteniendose con dichos indios todo el tiempo que duro la rebelion" ${ }^{27}$

En las circunstancias del avance al fuerte de Ledesma, el cacique Santiago le habría preguntado al capitán de Ledesma -según el registro de los testimonios realizado por el escribano- "si era cierto que tenian Rey", pero a diferencia de lo sucedido en la reducción -en la que aparentemente el teniente fue asesinado por su negación a aceptar aquello que se decía sobre el asunto-, no hubo violencia contra esta autoridad que habría respondido que "si, que todos siempre tenian Rey" ${ }^{28}$ Luego no lo volvemos a encontrar mencionado en las siguientes 
acciones colectivas ni como participante ni como prisionero. Tampoco aparece como testigo en el proceso judicial.

Una vez efectivizada la toma del fuerte de Ledesma y la incorporación de quienes lo estaban resguardando, se dieron dos intentos de efectuar la misma acción en el fuerte del Río Negro. Se lee en una deposición que "el animo de los principales asi de los indios como de sus aliados fue de que no matasen a ninguno de los soldados partidarios sino antes acariciarlos para que les ayudasen a la empresa que tenian principiada". ${ }^{29}$ Entre los testigos hay varios soldados partidarios de este fortín que fueron acusados de abandonar su puesto e incorporarse a la "parcialidad rebelde". Estimamos por los testimonios que salieron de su interior durante el desarrollo de los dos sitios, mayormente durante el segundo. ${ }^{30}$ Francisco Ranjel explicó que

se descolgo por las paredes del fuerte, y se fue a incorporar con los indios tovas y soldados christianos que estaban sitiando dicho fuerte" [porque] "su compañero el cordoves le havia influido que los blanquillos hiban a degollarlos a todos y quedarse en el fuerte..$^{31}$

El primer ensayo se sostuvo durante el martes 27 de marzo y consistió en cortar el suministro de agua del fuerte. El abandono del cerco se produjo por la intervención de Pedro Serrano, testigo que llegó a la ciudad desde los valles sur orientales para denunciar a las autoridades que un grupo de tobas y soldados partidarios lo habían reclutado en las cercanías del fuerte del Río Negro con el objetivo de atacar la ciudad. Según su testimonio -y otros que constatan sus dichos- como lo conocían fue nombrado "capitán" y por ese medio convenció a los otros de levantar el sitio. La "mucha confianza que de él tenían" le habría permitido separarse y escapar hacia la ciudad con la excusa de buscar más gente y llevarla a la "reunión" que se estaba produciendo en el Guaico Hondo. ${ }^{32}$

El segundo intento de tomar el Río Negro parece haberse iniciado el 28 de marzo, cuando los "conjurados" se enteraron de la traición de Serrano y se desplazaron desde el Guaico Hondo hacia distintos puntos. Mientras un fragmento continuó con la creación de una “junta” en las serranías de Zapla, otros se retiraron a rodear nuevamente el fuerte. Esta última decisión se habría tomado por la intervención del capitán de la fortificación de Santa Bárbara, quien se había visto envuelto en los movimientos cuando se desplazaba hacia el fuerte del Río Negro. Su incorporación, como la de Serrano, se produjo por un encuentro casual con parte de la gente movilizada en las cercanías del mismo. Nos hallamos frente a otra autoridad de las instituciones militares de la frontera respecto a la cual no se desata una violencia específica y cuyos consejos, además, fueron escuchados. Frente a la opinión de realizar el ataque a la ciudad de forma inmediata, el capitán del fuerte de Santa Bárbara sugirió retornar al Río Negro en un diálogo que pareciera que tuvo lugar de manera abierta -no circunscripto al grupo que luego fue acusado de cabecilla ni a los indígenas. En el trayecto hacia el fuerte, Gamero -como antes Serrano- abandonó el movimiento, se dirigió a la ciudad a dar parte de lo que ocurría y contribuyó a sofocarlo junto a los vecinos de la ciudad. ${ }^{33}$

Este segundo cerco al fuerte del Río Negro parece haber durado varios días. Participaron de él tanto los tobas como los soldados partidarios y algunas personas que progresivamente llegaron a sumarse a la acción a raíz de las convocatorias. Además de los consejos del capitán del fuerte de Santa Bárbara, el padre doctrinero de la reducción de San Ignacio habría aportado su parecer
29. AGI, Buenos Aires 143, Declaración de Melchor Ardiles, f. 56r. El resaltado en cursiva nos pertenece.

30. AGI, Buenos Aires 143, Autos del proceso judicial. Eran soldados del fuerte de Río Negro los testigos Francisco Ranjel, Melchor Ardiles, Roque Baca y los prófugos Manuel Orellana, Joaquín Ceballos y Pascual Andrade.

31. AGl, Buenos Aires 143, Declaración de Francisco Ranjel, fs. 51v-52r.

32. AGI, Buenos Aires 143, Declaración de Pedro Serrano, fs. $3 v-7 v$.

33. AGI, Buenos Aires 143, Declaraciones de Antonio Gamero, Juan José Almasán, Andrés López, Rafael Castillo, fs. 12r-14v, 66v, $73 v$ y $115 \mathrm{v}$. 
34. AGl, Buenos Aires 143, Declaración de Melchor Ardiles, f. $55 \mathrm{v}$. El resaltado en cursiva nos pertenece.

35. AGl, Buenos Aires 143, Declaración de Melchor Ardiles, f. 55v. Este testigo es el que más se explaya sobre las actuaciones del cura doctrinero, quien no declara en el proceso judicial. Suponemos que el "capitán León" al que se refiere en su testimonio es Fernando León, uno de los "dos cristianos" que estuvieron presentes en la "consulta general" en la que el vicario habría sugerido cómo hacerse del fuerte.

36. Contribuyeron en la ruptura del cerco del fuerte del Río Negro soldados de Jujuy dirigidos por Gregorio de Zegada, una guarnición de granaderos comandados por el teniente coronel de veteranos Cristóbal López y dos compañías de milicianos de Santiago del Estero y del Valle de Catamarca al mando de José Antonio Gorostiaga (AGl, Buenos Aires 467, Carta del gobernador del Tucumán Andrés Mestre al ministro José Gálvez, Jujuy, 24 de abril de 1781, s/f y Carta del gobernador del Tucumán Andrés Mestre al virrey Vértiz, Jujuy, o3 de abril de 1781, en De Angelis [1836] 1910: 273-274).

37. AGl, Buenos Aires 143. Declaración de Mariano Galarza, $f$. $64 r$.

38. Oficio de Gregorio Zegada al gobernador del Tucumán Andrés Mestre del $1^{\circ}$ de abril de 1781 , Jujuy, en De Angelis, [1836] 1910: 275-277; AGI, Buenos Aires 467. Carta del gobernador del Tucumán Andrés Mestre al ministro José Gálvez del 24 de abril de 1781, Jujuy. s/f.; Carta del gobernador del Tucumán Andrés Mestre al virrey Vértiz del 03 de abril de 1781, Jujuy, en De Angelis [1836] 1910: 273-274; AGl, Buenos Aires 143. Autos del proceso judicial.

39. AGI, Buenos Aires 143, Declaración de Martin Vidaurre, $f$. 19v.

40. AGI, Buenos Aires 143, Declaración de Lorenzo Serrano, fs. 4or-v. durante una "consulta general" que se realizó -según se infiere en la reducción- sobre el "modo en que havian de abanzar el fuerte", estando presentes "cuatro indios principales" y "dos cristianos". En esas circunstancias habría opinado que

procurasen no desmembrarse los soldados de los indios sino que antes como hermanos estubiesen firmes en su empresa...y fuesen a dicho Rio Negro el que facilmente lo ganarian sin mas trabajo que quitarles el agua, y esperar a que se seque el pozo que de unico ausilio les havia quedado, assi a los soldados como a los cavallos, y que assi lo verificaron. ${ }^{34}$

Esas fueron las acciones realizadas y en determinado momento la puerta del fuerte se abrió para recibir a una comitiva que establecería la forma en que sería entregado; entre los miembros estaba el cura de la reducción de San Ignacio, una escolta de indios y un tal “capitán" León. Sin embargo, la negociación se vio frustrada cuando su comandante recibió un comunicado desde la ciudad en el que se le advertía que se dirigía hacia allí una marcha de soldados que le prestaría auxilio. ${ }^{35}$

Cuando llegó el destacamento militar enviado desde la ciudad, el sitio al fuerte del Río Negro continuaba. ${ }^{36}$ El avance se produjo la madrugada del 3 o 4 de abril, los indios tobas y los "christianos" que lograron escapar se refugiaron en el monte. En su mayoría los que estaban en el sitio del fuerte confesaron que escaparon de los soldados -uno alegó que siguió el consejo del cura doctrinero para ello- ${ }^{37}$ y que luego fueron capturados en distintos lugares, permaneciendo prófugo un número indeterminado de personas cuando cerró el proceso judicial. Otra parte se habría mantenido oculta y habría intentado tomar el fuerte pasado un tiempo, lo que habría generado el retorno de las compañías enviadas desde la ciudad. ${ }^{38}$

\section{Mientras tanto...: convocatorias y reuniones}

Paralelamente a los cercos al fuerte del Río Negro y al intento de tomarlo para así incorporar a todos sus soldados partidarios y hacerse de las municiones que pudiese haber en él, otras personas se separaron para convocar gente por distintos parajes de la jurisdicción. Los "nuevos parciales" eran trasladados al paraje de Zapla donde se acordó continuar la reunión de sujetos para atacar la ciudad de Jujuy. En ese espacio quedó supervisando uno de los soldados de la reducción de San Ignacio, aguardaba a quienes fueran citados por los parajes de la jurisdicción y el regreso de quienes se habían dirigido al fuerte de Río Negro. Durante la espera llegó un "sastrecito" que al encontrarse con la gente reunida habría insinuado que iría a acusarlos a la ciudad, lo que desató la violencia hacia su persona y llevó a la pérdida de su vida. ${ }^{39}$

Las convocatorias que se realizaron en el Alto del Comedero sirven para comenzar a divisar esas otras formas con que parte de la población de los valles surorientales se integró a los movimientos, aparte de los encuentros fortuitos o de los sitios a los fuertes. En distintos testimonios se afirma que un grupo de personas esperaba al margen del camino para interceptar a quienes pasasen por allí y llevarlos compulsivamente hasta Zapla. Según el registro de la declaración de Lorenzo Serrano -quien fuera identificado por los otros testigos como reclutador en ese paraje- "los atajaba diciendoles cuidado con el que quisiese huir que le ha de costar la vida, y hemos de llevar sus cavezas a nuestros mandones, y assi no dejaban pasar a ninguno". ${ }^{40}$ Varios declarantes 
dijeron haberse vistos envueltos en esta situación, como aquel que informó que se estaba dirigiendo hacia la ciudad de Jujuy "con unos pollos [...] que había trocado por pan" cuando le cortaron el paso y no le dejaron continuar, trasladándolo a Zapla. ${ }^{41}$ Las expresiones relacionadas con aquello que estaban realizando estos testigos, cuando se cruzaron con los convocadores en los caminos, es algo regular en sus testimonios y en la mayor parte de los casos se trata de actividades cotidianas relacionadas con la vida en el espacio de los valles y con el tipo de labor que desarrollaba el deponente. Otro declarante describió una situación similar en la mesada de Palpalá donde dijo que "con ocasion de benir de su havitacion por ver a una hermana suia llamada Petrona...le salieron al encuentro nuebe sujetos...y que...viendose indefenso, se redujo a seguirlos" ${ }^{42}$ Entre la exposición de los testigos se lee también el caso de uno que había salido en búsqueda de leña para sus patrones ${ }^{43}$, de otros que estaban ensillando sus caballos y que se aprestaban a salir a campear ${ }^{44}$, de algunos que estaban pescando en la orilla de un río ${ }^{45}$ y de otros que estaban trabajando en sus oficios o chacras. ${ }^{46} \mathrm{El}$ sirviente de un cura de Tarija que se hallaba de tránsito hacia Buenos Aires habría llegado ante las autoridades para denunciar violencias sobre su persona $y$, al ser preguntado sobre ellas en el marco del interrogatorio a uno de los sospechosos, expuso que "estando buscando un macho que se le havia perdido de su requa en las immediaciones del Rio Blanco se encontro con Lorenzo Serrano que esta presente, y con otro hombre lo llevaron a un monte de gente". ${ }^{47}$

Al menos una parte de la compañía de cabos de Los Alisos terminó en la "junta" de Zapla de igual manera. Los habitantes de ese paraje ubicado al sur-este de la ciudad habían recibido la orden de contribuir en su defensa y se estaban trasladando con tal fin cuando fueron interceptados en el Alto del Comedero y amenazados, "a fuerza de sablazos", a reducirse. Los testimonios sugieren que el sargento del partido de Los Alisos se vio compelido, junto a veinte soldados que se trasladaban con él, por estos sujetos que esperaban en el Alto del Comedero. ${ }^{48}$ Antonio Humacata afirmó en su declaración que:

estaba viniendo [a la ciudad] con veinte soldados y le salio al encuentro Domingo Rojas y Lorenzo Serrano, con Gregorio riojano, quienes le dijeron que con la comunicacion que tenian con los indios tobas le librarian la vida al declarante si se unia con ellos y por el contrario moriria si entraba a la ciudad ${ }^{49}$

Al mismo tiempo se deslizan referencias, en la continuación de su testimonio, de que los tobas de la misión de San Ignacio lo habían hecho llamar previamente para que se reuniese con ellos y de que ya conocía la noticia que aseguraba que los españoles estaban matando a la "gente plebe":

\footnotetext{
haviendole embiado un expreso el dicho Quilaquila y su yerno nombrado Jose Severino al zerro donde estaba retirado con toda su familia, vino luego con el mismo expreso Gregorio riojano a la casa de dicho Quilaquila quien le dijo ser cierto que en esta ciudad estaban los chapetones matando a los naturales y de facto havian muerto dos, y que a la demas gente querian cojerla dentro de las trincheras para matarla, y persuadido de que hiciesen lo mismo con el y su gente ( $y$ haviendole dicho assimismo Quilaquila que los indios lo havian hecho llamar) penso escapar mejor en aquel partido y no teniendo cavallo para ir, se lo presto dicho Quilaquila y en el se fue a Zapla. ${ }^{50}$
}

Este tipo de convocatoria, por medio de mensajes enviados a través de diferentes intermediarios a un particular, se dio en otros parajes y constituye otra muestra de cómo operaron las relaciones previas como canales privilegiados
41. AGI, Buenos Aires 143, Declaración de Agustín Sánchez, f. $31 \mathrm{v}$

2. AGl, Buenos Aires 143, Declaración de José Toro, f. 23v.

43. AGI, Buenos Aires 143, Declaración de Manuel Bejerano, f. 35 r.

44. AGI, Buenos Aires 143, Declaración de Matías Pino, f. 225v.

45. AGl, Buenos Aires 143, Declaraciones de José Manuel Tintilai, Rafael Castillo, Antonio Fines, fs. 53V, 115r, 132r.

46. AGI, Buenos Aires 143, Declaración de Nicolás Cadena, Bernardo Sarapura y Nicolás Mancilla, fs. 45 r, 68r y 75 r.

47. AGI, Buenos Aires 143, Declaración de Lorenzo Serrano, f. 41r.

48. AGI, Buenos Aires 143, Declaraciones de Norberto Martínez, Juan Baldivieso, Lorenzo y Antonio Humacata, fs. 26v-28r, 28r-29v, 30V-32r, 123V-129v.

49. AGl, Buenos Aires 143, Declaración de Antonio Humacata, f. 124 r.

50. AGI, Buenos Aires 143, Declaración de Antonio Humacata, f. $124 \mathrm{v}$. 
51. AGl, Buenos Aires 143, Declaración de Lorenzo Serrano, fs. 4or-v. Otra exposición de tenor semejante afirmaba que el "concuñado del declarante...fue en solicitud del dicho y no haviendole encontrado le dejo encargado a Alexo Fuentes con mucha eficacia para que le diga al declarante se baya al paraje nominado [de Zapla] donde se hayaban los demas neofitos... y no haviendole encontrado dicho Fuentes le dejo recado a un muchacho llamado Juan quien se lo dijo", AGI, Buenos Aires 143, Declaración de Bartolomé Ríos, f. 17 r.

52. AGl, Buenos Aires 143, Declaración de Manuel Flores, fs. 3ov-r.

53. AGl, Buenos Aires 143 Declaración de Mariano Basualdo, f. $25 \mathrm{v}$.

54. AGI, Buenos Aires 143 Declaración de Juan José Almasán, f. 66 r.

55. Cuando fue posible determinar, señalamos en el mapa la localización de los parajes que procederemos a señalar.

56. AGI, Buenos Aires 143, Declaraciones de Esteban Juárez y Francisco Miranda, fs. 94v-97r y 36r-37r. Esteban Juárez y Francisco Miranda expresaron que estuvieron en la ciudad para contribuir en su defensa antes de verse envueltos en los movimientos.

57. AGI, Buenos Aires 143. Declaración de Miguel Gerónimo Mamani, f. 49v: "determinaron regresar al Rio Negro...haviendolo llevado al declarante para este efecto pusieron el cerco para rendirlo pero no hizieron demostracion ninguna de acometerlo porque decian esperaban a los matacos que ya tenian convocados, y les havian hecho chasque para con su ayuda dar el abanze". para la circulación de la información. Se observa por ejemplo el siguiente relato en el que el testigo afirma que:

lo hicieron llamar del paraje de Labayen donde avitaba, a la hazienda de San Lucas para que se juntase con los indios, y que luego que llego el declarante a dicho San Lucas le dijo el indio Malcoly que alli havia quedado aguardandolo, que caminase en alcanze de los indios y sus allegados que ya se havian benido para aca, y que en efecto lo hizo. ${ }^{51}$

Por otro lado, las convocatorias realizadas por grupos que desempeñaron esa tarea no se limitaron a esperar en los márgenes de los caminos sino que implicaron desplazamientos por la jurisdicción. Se lee en el documento referencias de que "indios y christianos" pasaron por las habitaciones incorporando a quienes encontraban y menciones de la presencia de citadores por la estancia de El Brete -inmediata a Zapla- invitando a "los peones" a reunirse con ellos. Manuel Flores expuso que lo buscaron en su casa "y le dijeron con imperio camina hombre para donde te llevaremos sin escusa alguna por que de lo contrario llevaremos tu cabeza a Zapla donde tenemos toda la gente convocada" ${ }^{52}$ No faltaron testigos que admitieron haberse acercado a tal paraje por curiosidad, independientemente de los llamados, al divisar de lejos a la gente reunida o que lo hicieron teniendo ya algún conocimiento sobre los movimientos:

y en este intermedio haviendo pasado a casa de Miguel Ortiz a sus diligencias diviso en el cerro de Zapla una tropa de gente y le dijo a dicho Ortiz bamos a ver que gente es aquella y que haze alli, y haviendo llegado al propio paraje los encontraron que estaban reclutados ${ }^{53}$

y entonzes se retiro el huiendo de dichos indios...sin incorporarse con ellos, pero que despues viendo que ya tenian muchos de su parte contemplando maiores ventajas en aquel partido se agrego a el voluntariamente ${ }^{54}$

De esta manera dijeron haberse visto involucrados aquellos testigos que atendían sus pequeñas chacras o que estaban vinculados al trabajo en haciendas y estancias de los valles surorientales en tanto peones, conchabados, arrimados, etc. La mayoría era de origen altoperuano y, como los soldados partidarios, aparecen en el proceso judicial como mestizos, criollos, indios o mulatos. Las convocatorias se concentraron fundamentalmente en el espacio de los valles surorientales. ${ }^{55}$ Se citó en los caminos del Alto del Comedero, en el paraje de Palpalá y de Zapla, en el paraje del Río Blanco, por la pampa de San Pedro y en el paraje de La Puerta. Algunos testigos dijeron haber recibido órdenes de convocar gente por Las Osas, El Simbolar y sus contornos y otros que ya había sido convocada la gente de El Paño y Almona. Además, el radio se extiende si consideramos que algunos dieron la noticia de que habían sido llamados los habitantes de Ocloyas, Humahuaca, Volcán y Los Hornillos y de que las convocatorias habrían entrado incluso a la ciudad. ${ }^{56}$ Asimismo, durante el segundo cerco al fuerte del Río Negro se habría estado a la espera de indígenas identificados como "matacos", una parcialidad chaqueña no reducida a los que se habría convocado. ${ }^{57}$ Según las declaraciones, los tobas habrían sido los encargados de realizar esta convocatoria a diferencia de las otras en las que tanto personas identificadas como criollas, mestizas e indios habrían participado. En circunstancias que aún nos resultan confusas, los soldados que se enviaron para desarticular los movimientos detuvieron alrededor de setenta "matacos bien armados", unos treinta muchachos y muchachas y a "la vieja que traian por adivina". Como se encontraban apostados en las cercanías del fuerte de Ledesma, las autoridades entendieron que buscaban integrarse 
a la "alianza" y fueron ajusticiados antes de llegar a la ciudad por orden del gobernador del Tucumán. ${ }^{58}$

\section{El devenir de un "partido" de "indios y christianos" en Jujuy}

Se observa en la reconstrucción realizada que no existió en el espacio de la ciudad, los valles surorientales y la frontera de Jujuy la realización de una convocatoria a presenciar la publicación de edictos o pasquines que invitasen a realizar un plan de acción a un gran número de personas en simultáneo, práctica que fue regular durante las insurrecciones en los Andes y que motivó una pesquisa en La Puna de Jujuy. ${ }^{59}$ Aun así, se evidencia una intensa circulación de información acerca del curso de las rebeliones en el norte andino y de la situación de la jurisdicción de Jujuy.

Las distintas novedades se comunicaron de manera oral. La coronación del "Rey Inka" en el Perú, la pronta eliminación de la "gente plebe" por los "españoles" o la organización de un movimiento entre una parte de la población para atacar la ciudad de Jujuy fueron noticias que se transmitieron entre los habitantes de ese espacio de la jurisdicción a partir de encuentros personales en distintos parajes y circunstancias. Algunas de estas ocasiones fueron propiciadas por "convocadores", como se denominó a quienes fueron enviados desde dentro del movimiento a distintos puntos para transmitir la información y así asegurar nuevos participantes. Otros momentos oportunos fueron los avances hacia los fuertes, contexto en el cual quienes estaban alrededor llamaban a conocidos o a quienes divisaban en su interior. Paralelamente, se asoma en los testimonios una intensa circulación de las noticias entre personas que no contaban con una vinculación específica a los movimientos que se estaban gestando. Sucedió que los testigos escucharon más de una vez las distintas noticias y rumores. Pudieron oírlo de un convocador, luego preguntar sobre ellas al toparse con alguien en los caminos y luego rememorarlas por hechos particulares que sufrían en sus personas -como la llegada durante la madrugada de soldados de la ciudad a su casa, el embargo de sus bienes o la destrucción de sus chacras. ${ }^{60}$

Creemos que podemos comenzar a señalar ciertos elementos sobre el posible significado del episodio para distintos grupos de la sociedad de Jujuy. Cabe mencionar que los primeros trabajos que abordaron el caso sostuvieron que se trataba de una "repercusión" de las insurrecciones andinas de fines del siglo XVIII, interpretación que fue retomada por otros investigadores y que suponía objetivos compartidos con las sublevaciones de los Andes dada una similar situación de explotación (Lewin, 1957; Acevedo, 1960; Poderti, 1997). Posteriormente, surgieron análisis que se centraron en las características específicas de las sociedades y del sistema colonial de la jurisdicción de Jujuy. A partir de esa base Sandra Sánchez (2002) sugirió que no había existido una identificación política con Tupac Amaru en el espacio oriental de Jujuy sino que su nombre había sido utilizado tanto por los plebeyos, para atacar un orden social que los desplazaba, como por las autoridades coloniales, para consolidar su dominación social, económica y política; mientras que los indígenas chaqueños habrían visto una oportunidad para irrumpir -como lo habían hecho en otras ocasiones- en las propiedades españolas y vengar años de expropiación y explotación. Así, el ataque a la ciudad habría formado parte de los ciclos regulares de enfrentamiento chaqueño a la dominación española, adquiriendo cierto carácter distintivo por la participación de una plebe disconforme -la que se entiende como la "verdadera protagonista"- y por "la puesta en escena"
58. AGl, Buenos Aires 467, Carta del gobernador del Tucumán Andrés Mestre al ministro José Gálvez del 24 de abril de 1781, Jujuy, s/f. Carta del gobernador del Tucumán Andrés Mestre al virrey Vértiz del 24 de abril de 1781, Jujuy, en De Angelis [1836] 1910: 283. Autos de información de servicios iniciados por solicitud de Gregorio de Zegada, 21 de septiembre de 1781, Jujuy (transcripto en Sánchez, 2002).

59. Ver nota al pie 1 en la que nos referimos a la apertura de una causa paralela -posteriormente incorporada al expediente- en la Puna de Jujuy a raíz de la llegada de edictos atribuidos a Damaso Katari. Flores Galindo (1986) y Walker (2015) abordan en sus respectivas investigaciones la utilización de edictos y bandos en la región del Cusco.

6o. Un ejemplo concreto es el de Matías Pino. AGl, Buenos Aires 143, declaración de Matías Pino, fs. 225r-228v. 
61. AGl, Buenos Aires 143, Declaración de José Quiroga, f. 223r.

62. AGl, Buenos Aires 143, Declaración del Negro Justo, f. 11r.

63. AGI, Buenos Aires 143, Ratificación de Martín Vidaurre, fs. $83 v-84 r$.

64. AGI, Buenos Aires 143, Autos del proceso judicial.

65. AGI, Buenos Aires 143, Ratificación de Diego Avalos, fs. 101v-102r. El resaltado en cursiva nos pertenece.

66. AGl, Buenos Aires 143, Declaraciones de Mariano Galarza, Manuel Bejerano, Francisco Ranjel, Juan José Almasán y Antonio Humacata; Ratificaciones de Juan Ossorio, Mariano Bejerano y Juan de Dios Maldonado, fs. 63v, $89 \mathrm{v}, 53 \mathrm{r}$, $66 r-66 v$ y $124 v ; 81 v-82 r, 89 r-89 v$ y 91r-91v.

67. Diccionario de la Real Academia Española (1737). que hizo esta última "del nombre del Rey Inka". En contraposición, Enrique N. Cruz $(2006,2011)$ argumentó que se trató de una "rebelión toba" liderada por mestizos. Sus trabajos se centran en demostrar la existencia de distinciones "protoclasistas" en el espacio de la frontera oriental y de un liderazgo de tipo "carismático", detentado durante la "rebelión", por quien fuera acusado por las autoridades coloniales de ser el principal cabecilla -el criollo José Quiroga. Nuestra lectura buscó precisar las circunstancias en que sujetos o grupos diferentes se integraron a los movimientos y decidieron colaborar en la ejecución de prácticas concretas. La serie de acciones colectivas que identificamos -que en parte fueron planificadas y en parte fueron improvisadas según lo que acontecía- nos ilumina sobre las nociones y concepciones políticas que ciertos sectores de la población de Jujuy llegaron a compartir, al punto de generar solidaridades y adherir a un posible fin común. Tratamos, en definitiva, de recuperar el carácter dinámico de la movilización y de los actores.

Retomando nuestro propio análisis documental, observamos que en general todos los testigos expusieron que el objetivo "conversado" entre "indios y christianos" era el de atacar la ciudad de Jujuy. Un grupo importante mencionó que el fin era eliminar a todos sus habitantes "españoles", sin ningún tipo de excepción, y apropiarse de sus caudales, casas, haciendas y mujeres -a quienes volverían sus "esposas" o "esclavas". Otros restringieron la aniquilación a quienes no aceptasen ser vasallos de Tupac Amaru y retirarse -si este era el caso- a las tierras de "su" rey -es decir, del rey español Carlos III-, ${ }^{61}$ mientras que algunos aludieron a que no se procuraba la total eliminación de los españoles al afirmar que estos "havian de tener el exercicio que aora tenian los indios" ${ }^{62} \mathrm{o}$ al decir que "la gente baja [...] havian de estar conforme aora estaban los españoles y que estos havian de hazer el oficio de los plebeios". ${ }^{63}$ El motivo esgrimido para ello fue la circulación de aquella otra noticia que aseguraba que los "españoles" estaban matando a la "gente plebe" y a los indios de la jurisdicción -o lo harían de forma inminente-, que se vinculó a las novedades sobre "la coronación del Rey Inka" en el Perú a partir de las cuales se sostenía que aquel velaba por estos dos últimos grupos. ${ }^{64}$

Los testimonios nos sugieren entonces la cristalización de un objetivo compartido -atacar la ciudad de Jujuy- relacionado con una visión acordada sobre quién era el enemigo -el sector español residente en la ciudad con propiedades e intereses económicos en los valles-, cuyo lugar político-social se vería trastocado por su expulsión, desplazamiento o aniquilación si la "descubierta alianza" lograba imponerse.

¿Qué rasgos tenía esta unión entre "indios y christianos"? Un conchabado de la estancia del gobernador de armas explicaba en su ratificación que "como entonzes le dijesen que en esta ciudad estaban matando a todos los de baja esfera tomo por mejor partido el de los indios y se agrego a ellos".$^{65}$ En otras deposiciones del proceso judicial aparece igualmente esta idea de la existencia de un "partido", que resultaría más favorable para los grupos, que el orden colonial procuraba mantener en un lugar subordinado o incluso -según las noticias- su eliminación. ${ }^{66}$ Para principios del siglo XVIII el Diccionario de la Real Academia Española (1737) definía al "partido" como "parcialidad o coligación entre los que siguen una misma opinión o interés", o también como "el conjunto o agregado de personas que siguen y defienden una misma sentencia, opinión o dogma" ${ }^{67}$ En el caso que nos ocupa, el mismo es identificado en la documentación judicial a partir de su componente indígena, más específicamente, por los "tobas" reducidos aunque se desprende de los testimonios que los "matacos" también lo integraban en tanto habrían sido convocados en común acuerdo. 
Asimismo -y a pesar de que los testigos van a buscar distanciarse- se infiere que incluía orgánicamente a los criollos, indios, cholos, mulatos y mestizos que habitaban y trabajaban en el espacio de los valles surorientales o que estaban en la ciudad en carácter de sirvientes o cautivos de los españoles. Es decir: al conjunto de la "gente plebe".

Internamente no parece haber primado un grupo sobre otro: el cacique Santiago tomaba decisiones y era consultado en carácter de autoridad del movimiento, quienes fueron designados como "capitanes" dieron órdenes pero acataron las decisiones grupales -como realizar el segundo sitio al fuerte del Río Negro antes de avanzar sobre la ciudad- y tanto "indios" como "christianos" estuvieron presentes en momentos importantes -cuando se da muerte al teniente de la reducción, cuando se produce la "consulta general" sobre el avance al fuerte de Río Negro, cuando entra una comitiva para consensuar la posteriormente frustrada entrega del mismo, cuando convocadores salieron por los caminos, etc.

Entendemos que entre los miembros del "partido" se cristalizó la idea de la existencia de un vínculo de parentesco, de similares condiciones de opresión y de expectativas políticas compartidas. ${ }^{68}$ Sobre esa base, algunos objetivos se fueron definiendo sobre la marcha y las declaraciones están permeadas por la existencia de "juntas", "reuniones" o "consultas" en las que se discutían las opciones a seguir entre una parte importante de los colaboradores. El registro de las declaraciones muestra la síntesis de estos procesos de toma de decisiones o de la conformación de los objetivos, mientras que las prácticas concretas complejizan nuestra percepción sobre los vínculos sociales, las identificaciones y la conformación de solidaridades en este espacio. Así, por ejemplo, si bien en las enunciaciones sobre el destino de los "españoles" predomina la opción de su total eliminación, en la práctica vemos sujetos que pudieron haberse considerado como tales o como "chapetones" o "blanquillos" ${ }^{69}$ y fueron integrados en los movimientos: los capitanes de los fuertes estuvieron frente a la gente movilizada y corrieron distinta suerte. ${ }^{70}$ La diferente resolución parece no haber dependido tanto de su cargo o adscripción étnica sino de la postura política que estas autoridades adoptaban respecto a los objetivos esgrimidos por quienes se movilizaron. Nos animamos a afirmar que el tipo de relación previa también influyó en su suerte; se lee en el expediente que durante la toma del fuerte de Ledesma "no mataron al capitan porque lo querian los indios". ${ }^{71}$ Estos dos elementos -opción política y tipo de vínculo desarrollado previamente- pueden explicar por qué el teniente de la reducción de San Ignacio no fue perdonado, mientras los comandantes de Ledesma y de Santa Bárbara sí. Cabe recordar que el cura de la reducción de San Ignacio era parte integrante de los movimientos -dando incluso su parecer- y que un sastrecito -que debiera haber sido considerado como parte del mismo- fue eliminado en la reunión de Zapla por sugerir que denunciaría la junta.

El gobernador del Tucumán y su teniente y justicia mayor, los cabildos españoles de Jujuy y Salta y los fiscales de la causa, otorgaron versiones sobre los movimientos, concordantes entre sí, en sus informes y en la resolución del juicio. En general -ya prevenidos y alarmados por el curso de las rebeliones andinas- centraron su argumentación en resaltar que resultaban del "contagio" que había llegado desde las "provincias de arriba". En esta lógica de la existencia de una "propagación", las motivaciones que habrían tenido los tobas de la frontera oriental de Jujuy para abandonar su reducción fueron representadas como una mecánica respuesta a la "impresión imponderable" que sobre ellos habría causado el nombre de Tupac Amaru. Respecto a la "gente común" se recalcó su falta de lealtad y tampoco se les atribuyó el
68. AGI, Buenos Aires 143, Declaración de Antonio Humacata, f. 124v. En esta deposición se afirma que el cacique Santiago llamó al declarante y le refirió que los "chapetones" matarían a "todos los pobres" y que los tobas querían defenderlos al ser "parientes" y "de la propia sangre". Asimismo, se registró que el testigo dijo que aquella autoridad étnica le manifestó que "los chapetones solo quieren tener Rey y no quieren que nosotros lo tengamos".

69. Las tres denominaciones aparecen en los testimonios del proceso judicial.

70. Gullón Abao (1993) señaló que los comandantes fueron grandes beneficiarios del avance de la frontera.

71. AGI, Buenos Aires 143, Declaración de Andrés López, f. 73r. 
mérito de tener algún proyecto o motivación genuina que fuera más allá del enriquecimiento individual la codicia y la ambición. Se sostuvo que no había motivos de "descontento" o "resentimiento" ni "fatigas" o "extorciones" en la jurisdicción que explicasen una rebelión (Glatstein, 2017).

A pesar de los argumentos sostenidos por las autoridades militares y judiciales, las prácticas, los objetivos y las razones que dieron los testigos nos hacen pensar en tensiones específicas entre los vecinos principales del ámbito urbano y la población rural. En la ciudad habitaba la mayor parte de los españoles y la elite de la jurisdicción, que había acumulado la posesión de la tierra, se beneficiaba considerablemente del comercio y detentaba el poder político local. El progresivo avance en la posesión de la tierra -de hecho o a través de mercedes- por parte de españoles peninsulares o sus descendientes parece haber estado entre los motivos, como así también su puesta en producción con el trabajo de los migrantes altoandinos, los soldados partidarios y los indígenas chaqueños. Nos resta poder ahondar sobre los términos en que se daba tal vínculo pero resulta significativo que los testigos hayan resaltado la intención de invertir los términos de la relación para dejar de ser "esclavos" de los "españoles". Además, para los chaqueños que se habían asentado en la misión de San Ignacio la decadencia de ésta debe haber languidecido el pacto sobre el que se cimentó su reducción, incrementado su recelo el terminar siendo usados como mano de obra por los comandantes de los fuertes y de las fronteras en sus respectivas estancias y haciendas. Asimismo, en el contexto de los movimientos los milicianos que se encontraban en la ciudad solicitaron un aumento de su pago por sus servicios en las trincheras, y en los testimonios se destaca que la plata de las cajas reales sería destinada a efectivizar la paga de los soldados partidarios, lo que indica la existencia de otro conflicto con estos actores.

En suma, entendemos que nos encontramos ante una organización política que se fue definiendo y significando a partir de prácticas y visiones compartidas. En un contexto cargado de rumores y temores respecto a los acontecimientos de la guerra anticolonial en el Alto y Bajo Perú aparece este movimiento enraizado en problemáticas sociales específicas a la jurisdicción de Jujuy. Pasando de largo por ahora la iniciativa "individual" del criollo José Quiroga, observamos que velozmente se conformó un núcleo de soldados partidarios e indígenas "tobas" reducidos que comienza a actuar conjuntamente. Cimentada sobre los lazos sociales e identitarios que se construyeron en el espacio suroriental desde mediados del XVIII, la síntesis de la unión se expresó en la existencia de un vínculo de parentesco y en las menciones sobre la conformación de un "partido" que les aglutinaba. También visualizamos que las prácticas colectivas de esta naciente entidad no estuvieron pactadas de antemano y algunas se interrumpieron o modificaron en plena ejecución. Las decisiones se tomaron sobre la marcha y en varias ocasiones en reuniones improvisadas en las que no se observa una discriminación o jerarquización sobre quiénes estaban autorizados a brindar su opinión y a decidir. El análisis de los testimonios muestra que existieron numerosas instancias de discusión en las que la participación fue abierta a todos los que integrasen el "partido", aunque su incorporación hubiese sido reciente. Tanto los avances sobre los fuertes como las convocatorias por la jurisdicción parecen formar parte de estas resoluciones que se tomaron en conjunto, para hacer efectivos otros objetivos pautados. Entre ellos se cuenta el ataque a la ciudad de Jujuy, que aparentemente se definió de forma temprana y se aplazó ante la necesidad de contar con mayor número de adeptos y armamento. Esta percepción fue especialmente fomentada por algunas personas que entraron al movimiento por coacción y que deseaban 
ganar tiempo para salirse de él y alertar a las autoridades. Fuera de los testigos que no mostraron interés en ser partícipes de la alianza o que resaltaron el carácter intimidante de las convocatorias, muchos otros admitieron que buscaron integrarla decididamente en función de los objetivos propuestos y otros ante el temor que les generó la inminente represalia de los españoles -en consonancia con los rumores que circulaban. También se cuelan entre los testimonios menciones de personas que estaban a la espera de ver el resultado de los enfrentamientos para sumarse a quienes saliesen victoriosos.

Consideramos -aún a manera de hipótesis- que en este espacio de la jurisdicción se estaba llevando a la práctica -como en otras áreas de los Andes, pero con contenidos y circunstancias locales definidos- un intento de opción anticolonial $^{72}$ en la que la sociedad imaginada suponía una integración multiétnica de individuos que habitaban en las tierras bajas y en la ciudad. Potencialmente habría buscado agregar a habitantes de la Quebrada de Humahuaca, ya que los testimonios hablan de que se habían enviado convocadores a pueblos que están ubicados allí. ${ }^{73}$ Carecemos de indicios acerca de una intención similar respecto a los pueblos de las tierras altas de la jurisdicción. No podemos saber qué sucedería definitivamente con aquellos considerados como "españoles" en el ataque a la ciudad, ya que las autoridades coloniales se aseguraron de desarticular velozmente la "alianza" y nunca se concretó el avance; no obstante, pareciera -por las prácticas que sí sabemos tuvieron lugar en los valles surorientales- que se habría admitido la pervivencia de estos sujetos, pero en un lugar elegido por el "partido" de "indios y christianos".

\section{Agradecimientos}

Agradecemos los comentarios a versiones anteriores de este trabajo realizados por Estela S. Noli y por los evaluadores anónimos.
72. Recuperamos de Sinclair Thomson ([2006] 2010: 201) el concepto de "proyecto anticolonial" que implica la participación de aquellos que "desafían explícita y conscientemente los fundamentos del orden político colonial: la soberanía española y la subordinación política de los indios", pudiendo implicar “1) El repudio o desplazamiento del rey de España (al reemplazarlo, por ejemplo, por un rey Inka); 2) el rechazo a la subordinación política indígena (sea a través de la subordinación de los españoles o de la equivalencia entre los dos pueblos); y 3) la afirmación de la autonomía indígena (a través del rechazo a la corona y a las autoridades españolas en el territorio americano, y en este caso, en territorio andino)"; incluyendo como instancia posible en la imaginación anticolonial, "la postura de aniquilación".

73. No hay testigos que dijesen provenir de la Quebrada tras una convocatoria concreta, queda el interrogante al respecto. Sandra Sánchez (2002) sostuvo la hipótesis de que los pueblos de la Quebrada no participaron dada cierta visión negativa de estos sobre los habitantes de las tierras bajas. 


\section{- Fuentes inéditas citadas}

" Archivo General de Indias (AGl)

»AGI, Buenos Aires 143. Autos del proceso judicial, Jujuy, 1781.

»AGl, Buenos Aires 467. Carta del gobernador del Tucumán Andrés Mestre al ministro José Gálvez, Jujuy, 24 de abril de 1781, sin foliación (s/f). 


\section{Q Bibliografía}

"Acevedo, E. O. (1960). Repercusión de las sublevaciones de Tupac Amaru en Tucumán. Revista de Historia de América 49: 85-119.

"De Angelis, P. [1836] 1910. Colección de obras y documentos relativos a la historia antigua y moderna de las provincias del Río de la Plata. Buenos Aires, Librería Nacional de J. Lajoune.

» Diccionario de la Real Academia Española (1737). Disponible en: http://web.frl.es/ DA.html. Consultado el: 9 de marzo de 2018.

»Cruz, E. N. (2006). Dominación y liderazgo carismático en la frontera del Chaco de Jujuy (Río de la Plata). La rebelión toba de 1781. Claroscuro 5: 263-288.

» Cruz, E. N. (2011). Diversidad y distinción social en una rebelión indígena y mestiza. El caso de la rebelión toba de 1781 en la frontera del Chaco de Jujuy (Argentina). Estudios Sociales 7: 169-190.

" Farberman, J. (2009). "Etnicidad y crimen. Sociedad colonial y adscripciones socioétnicas en Santiago del Estero, siglos XVIII y XIX" en Sozzo, M. (coord.), Historias de la cuestión criminal en Argentina: 31-6o. Buenos Aires, Del Puerto.

" Farge, A. y J. Revel ([1988] 1998). Lógica de las multitudes. Secuestro infantil en París, 1750. Rosario-Argentina, Homo Sapiens Ediciones.

»Flores Galindo, A. (1986). Buscando un Inca: identidad y utopía en los Andes, Cuba, Ediciones Casa de las Américas.

» Garavaglia, J. C. (1984). La guerra en el Tucumán colonial: Sociedad y economía en un área de frontera (1660-1760). Revista Latinoamericana de Historia Económica y Social IV: 21-34.

» Glatstein, L. (2017). Estando el fuego a las puertas. Acciones y representaciones de la justicia colonial (Jujuy, 1781). Anuario de Estudios Americanos 74 (2): 525-555.

» Gullón Abao, A. (1993). La frontera del Chaco en la Gobernación del Tucumán 1750-1810. Cádiz, Universidad de Cádiz.

" Joseph, G. M. y D. Nugent (comps.) (2002). Aspectos cotidianos de la formación del Estado. La revolución y la negociación del mando en el México moderno. México, Ediciones ERA.

"Larson, B. (1992). Explotación y economía moral en los Andes del Sur. Hacia una reconsideración crítica. Crítica 6: 75-97.

»Lewin, B. (1957). La rebelión de Túpac Amaru y los orígenes de la independencia de Hispanoamérica. Buenos Aires, Hachette.

» Lorandi, A. M. (1980). La frontera oriental del Tawantinsuyu: el Umasuyu y el Tucumán. Una hipótesis de trabajo. Relaciones de la Sociedad Argentina de Antropología XIV (1): 147-164.

"Lucaioli, C. (2009). Construcción de territorios: percepciones del espacio e interacción indígena y colonial en el Chaco Austral hasta mediados del siglo XVIII. Antípoda 8: 117139.

"Lucaioli, C. (2010). "Los espacios de frontera en el Chaco desde la conquista hasta mediados del siglo XVIII" en Lucaioli, C. y L. Nacuzzi (comps.), Frontera. Espacios e interacción en las tierras bajas del sur de América: 21-68. Buenos Aires, Sociedad Argentina de Antropología. 
» Lucaioli, C. y F. Nesis (2007). Apropiación, distribución e intercambio: el ganado vacuno en el marco de las reducciones de abipones y mocoví (1743-1767). Andes 18: 129-152.

» Mata de López, S. (2005). Las fronteras coloniales como espacios de interacción social. Salta del Tucumán (Argentina), entre la Colonia y la Independencia. Dimensión Antropológica 33: 69-90.

» Nacuzzi, L. (2007). Los grupos nómades de la patagonia y el chaco en el siglo XVIII: identidades, espacios, movimientos y recursos económicos ante la situación de contacto. Una reflexión comparativa. Chungara 39 (2): 221-234.

» Paz, G. (1997). Familia, linaje y red de parientes: la elite de Jujuy en el siglo XVIII. Andes 8: $147-174$.

» Poderti, A. (1997). Palabra e historia en los Andes. La rebelión del Inca Tupac Amaru y el Noroeste argentino. Buenos Aires, Ediciones Corregidor.

» Rasini, B. (1965). Estructura demográfica de Jujuy, siglo XVIII. Anuario del Instituto de Investigaciones Históricas: 119-150.

»Sánchez, S. (2002). "Se hace camino al andar. Tupac Amaru en Jujuy. Una reinterpretación". Tesis de Magister en Historia con Mención en Etnohistoria. Santiago de Chile, Facultad de Filosofía y Humanidades - Universidad de Chile (Ms. inédito).

» Sánchez, S. y G. Sica (1997). “Por ser gente de otra ley”. Tobas, mocovies y ojotaes reducidos en el valle de Jujuy. Prácticas y discursos (siglos XVII y XVIII). Journal de la Société des Américanistes 83: 59-80.

"Scott, J. C. ([1976] 1977). The Moral Economy of the Peasant. Rebellion and Subsistence in Southeast Asia. Londres, Yale University Press.

»Serulnikov, S. (2006). Conflictos sociales e insurrección en el mundo colonial andino. El norte de Potosí en el siglo XVIII. Buenos Aires, Fondo de Cultura Económica.

» Stern, S. J. ([1987] 1990a). “Nuevas aproximaciones al estudio de la conciencia y las rebeliones campesinas: las implicancias de la experiencia andina” en Stern, S. J. (comp.), Resistencia, rebelión y conciencia campesina en los Andes. Siglos XVIII al XX: 25-41. Lima, Instituto de Estudios Peruanos (IEP).

» Stern, S. J ([1987] 1990b). “La era de la insurrección andina, 1742-1782: una reinterpretación” en Stern, S. J. (comp.), Resistencia, rebelión y conciencia campesina en los Andes. Siglos XVIII al XX: 50-96. Lima, IEP.

» Teruel, A. (1994). Zenta y San Ignacio de los tobas. El trabajo en dos misiones del Chaco occidental a fines de la colonia. Anuario del IEHS 9: 227-252.

» Thompson, E. P. ([1971] 1979). “La economía moral de la multitud” en Thompson, E. P. Tradición, revuelta y consciencia de clase. Estudios sobre la crisis de la sociedad preindustrial: 62-134. Barcelona, Crítica.

» Thomson, S. (2003). “'Cuando sólo reinasen los indios’: Recuperando la variedad de proyectos anticoloniales entre los comunarios andinos (La Paz, 1740-1781)" en Hylton, F.; Patzi F; Serulnikov, S. y S. Thomson, "Ya es otro tiempo el presente". Cuatro momentos de insurgencia indígena: 39-77. La Paz, Muela del Diablo Editores.

» Thomson, S. ([2006] 2010). Cuando sólo reinasen los indios. La política aymara en la era de la insurgencia. La Paz, La Mirada Salvaje.

»Vitar, B. (1991). Las relaciones entre los indígenas y el mundo colonial en un espacio conflictivo: la frontera tucumano-chaqueña en el siglo XVIII. Revista Española de Antropología Americana 21: 243-278.

»Vitar, B. (1997). Guerra y misiones en la frontera chaqueña del Tucumán (1700-1767). Madrid, CSIC.

»Walker, C. (2015). La rebelión de Tupac Amaru. Lima, IEP. 